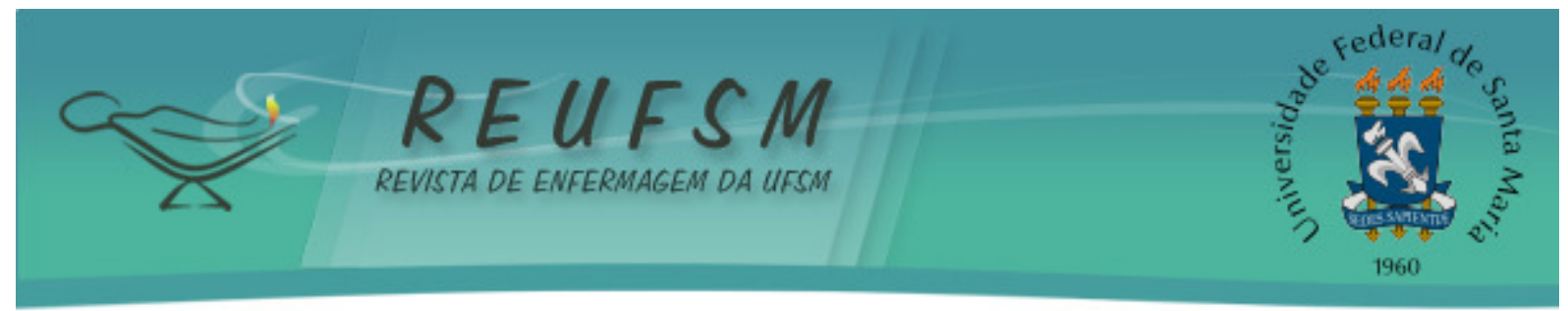

ARTIGO DE REFLEXÃO

\title{
O AGIR COMUNICATIVO DO ENFERMEIRO NA ASSISTÊNCIA AO PACIENTE CRITICAMENTE ENFERMO
}

\author{
NURSE'S COMMUNICATIVE ACT IN THE CARE TO THE CRITICALLY ILL PATIENT \\ EL ACTO COMUNICATIVO DEL ENFERMERO EN LA ATENCIÓN AL PACIENTE \\ CRIITICAMENTE ENFERMO
}

\author{
Kelly Karine Sales Zem ${ }^{1}$ \\ Fabíola Schirr Cardoso ${ }^{2}$ \\ Juliana Helena Montezeli ${ }^{3}$
}

Doi: $10.5902 / 2179769291577419$

RESUMO: Objetivo: refletir sobre o agir comunicativo do enfermeiro na assistência ao paciente crítico. Método: trata-se de uma reflexão teórica. Resultados: foram construídas duas categorias reflexivas, sendo que na primeira se fez uma breve explanação sobre a Teoria do Agir Comunicativo, de Jürgen Habermas, a qual serviu como pano de fundo para a segunda etapa da reflexão, que teceu considerações acerca das interfaces da referida teoria com a atuação do enfermeiro na prestação de cuidados a indivíduos criticamente enfermos. Conclusão: por meio da análise da literatura conclui-se que o referencial teórico em questão pode contribuir para a humanização da assistência de enfermagem ao paciente em estado crítico, uma vez que, ao submeter suas atitudes a um agir comunicativo, o enfermeiro estará em busca de uma maior interação com o paciente, a família, sua equipe e os demais profissionais da saúde.

Descritores: Enfermagem; Comunicação; Cuidados críticos.

ABSTRACT: Objective: reflect on the nurse's communicative act in the care to the critical patient. Method: this is a theoretical reflection. Results: two reflective categories were constructed, in the first there was a brief explanation of Jürgen Habermas' Theory of Communicative Act, constituting a backdrop for the second reflection stage, which presented considerations on the interfaces of that theory with the nurse's action when providing critically ill individuals with care. Conclusion: through literature analysis, one concludes that the theoretical framework concerned may contribute to the humanization of nursing care to the patient in a critical condition, since, by submitting his attitudes to a communicative act, the nurse will be in search of a greater interaction with the patient, the family, his team, and the other health professionals.

Descriptors: Nursing; Communication; Critical care.

RESUMEN: Objetivo: reflexionar acerca del acto comunicativo del enfermero en la atención al paciente crítico. Método: es una reflexión teórica. Resultados: fueron construidas dos categorías reflexivas, en la primera hubo una breve explicación acerca de la Teoría del Acto Comunicativo, de Jürgen Habermas, que sirvió de escenario para la segunda etapa de reflexión, que tejió consideraciones acerca de las interfaces de esa teoría con la actuación del enfermero

\footnotetext{
${ }^{1}$ Enfermeira. Especialista em Assistência de Enfermagem ao Paciente Crítico pela Faculdade Evangélica do Paraná (FEPAR). Enfermeira do Hospital das Nações, Curitiba, PR, Brasil. E-mail: kellyzem@hotmail.com

${ }^{2}$ Enfermeira. Mestre em Educação pela Universidade Tuiuti do Paraná. Professora da Faculdade Evangélica do Paraná, Curitiba,PR, Brasil. E-mail: f.schirr@hotmail.com

${ }^{3}$ Enfermeira Emergencista. Mestre em Enfermagem pela Universidade Federal do Paraná (UFPR). Professora Assistente no Departamento de Enfermagem da Universidade Estadual de Londrina (UEL), Londrina,PR, Brasil. E-mail: jhmontezeli@hotmail.com
} 


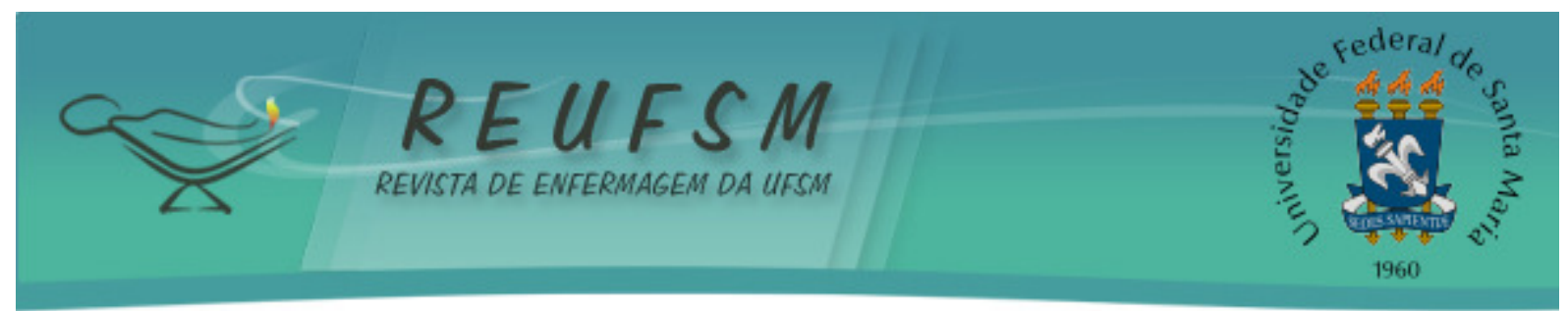

en la atención a individuos críticamente enfermos. Conclusión: por medio del análisis de la literatura se concluye que el referencial teórico en cuestión puede contribuir a la humanización de la atención de enfermería al paciente en estado crítico, ya que, al someter sus actitudes a un acto comunicativo, el enfermero estará en búsqueda de una mayor interacción con el paciente, la familia, su equipo y los demás profesionales de la salud.

Descriptores: Enfermería; Comunicación; Cuidados críticos.

\section{INTRODUÇÃO}

A habilidade de se comunicar é fundamental para o desenvolvimento do trabalho do enfermeiro perante a equipe multiprofissional e de enfermagem. Além disso, representa um pilar de sustentação para a assistência a pacientes e familiares.

O ser humano utiliza a comunicação para fornecer informações, para persuadir, de forma a gerar mudanças de comportamento, para ensinar e para discutir qualquer tema. ${ }^{1}$ Logo, o processo de comunicação é intrínseco às ações de enfermagem, cabendo ao enfermeiro compreender o significado das mensagens que os pacientes emitem. ${ }^{2}$

A internação hospitalar é sempre uma experiência desagradável por quem vivencia, pois é permeada pelo medo do desconhecido, pela utilização de recursos tecnológicos, muitas vezes invasivos e dolorosos, pela inquietação de estar em um local desconhecido, entre outros fatores. A verdade é que, por ser o membro da equipe multiprofissional que permanece mais tempo com o paciente, temos como objeto de trabalho o cuidado que procura estabelecer vínculo, construir relações e conhecer o outro. A interação entre cuidador e ser cuidado se apresenta como possibilidade de uma prática assistencial humanizada. ${ }^{3}$

Destarte, as habilidades comunicacionais do enfermeiro são ferramentas essenciais à assistência aos pacientes críticos, pois em um ambiente em que há ruídos, sons, emergências, agitação e não entendimento sobre seu estado de saúde e dos demais, acaba por gerar medo e insegurança nos pacientes. Clientes lúcidos e conscientes percebem tudo o que acontece ao seu redor, bem como toda assistência prestada a eles. Já aos pacientes com incapacidade de comunicação tais sentimentos podem ser potencializados. Neste cenário a relação estabelecida entre os atores sociais (enfermeiro, equipe, paciente, família) que interagem durante o cuidado de enfermagem e seus respectivos compromissos sociais deve ser exercida dentro de um agir comunicativo. ${ }^{4-5}$

O agir comunicativo é um processo circular, no qual um ator social é simultaneamente iniciador e produto do seu agir. Os participantes da comunicação precisam ter competência para adotar, se necessário, uma postura objetiva (no que tange a coisas existentes), uma atitude conforme as normas (no tocante às relações interpessoais legitimamente reguladas) e uma atuação expressiva (no concernente às suas próprias experiências). A consequência dessas atitudes competentes é o agir comunicativo. ${ }^{6-7}$

Com vistas a subsidiar o seu agir, a enfermagem deve buscar elementos das ciências sociais. Isso permite relacionar a vida dos indivíduos com o tempo histórico da sociedade. Neste contexto, é importante que esta categoria profissional esteja sensibilizada sobre a importância da comunicação no processo de cuidar; afinal, essa atitude pode transformar a relação enfermeiro-paciente e torná-la mais humanizada. ${ }^{4}$

Levando em consideração que o agir do enfermeiro com seu público-alvo tem como finalidade a promoção/recuperação da saúde em um rico contexto de relações interpessoais, é fato que uma atitude comunicativa deve ser um ato de extrema relevância para os profissionais que atuam diretamente sobre o cuidado. ${ }^{8}$ Assim, este estudo teve como objetivo refletir acerca da aplicação da teoria de Habermas em relação ao agir do enfermeiro com pacientes criticamente enfermos. 


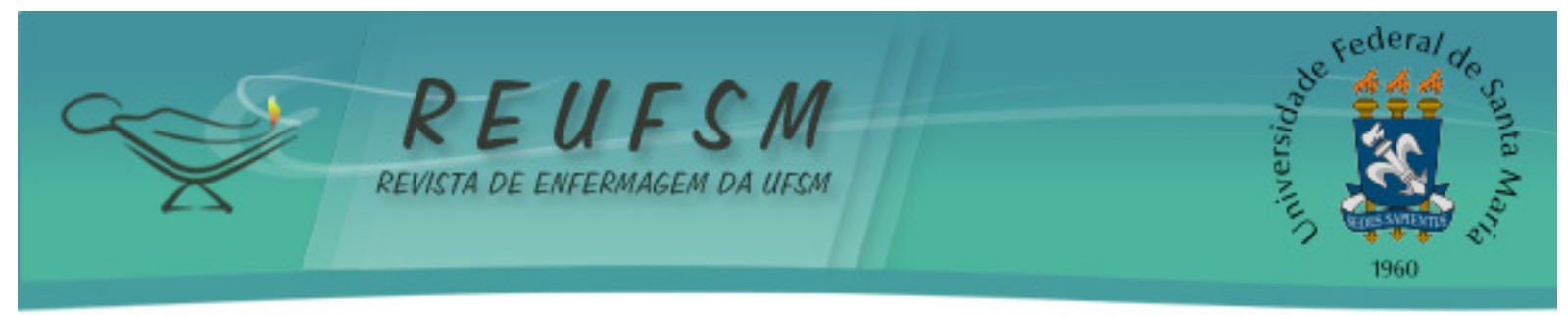

MÉTODO

Trata-se de uma reflexão teórica realizada a partir de levantamento bibliográfico da literatura correlata em periódicos, teses e materiais disponíveis on line, tendo como eixo norteador os descritores: Enfermagem, Comunicação e Cuidados críticos.

A partir dos achados no estado da arte foram identificadas duas categorias reflexivas, sendo que na primeira se fez uma breve explanação sobre a Teoria do Agir Comunicativo, de Jürgen Habermas, a qual serviu como pano de fundo para a segunda etapa da reflexão, que teceu considerações acerca das aplicações da referida teoria com a atuação do enfermeiro na prestação de cuidados a indivíduos criticamente enfermos.

\section{REFLEXÕES}

\section{Teoria da ação comunicativa de Jürgen Habermas: uma breve revisão}

Jürgen Habermas estudou filosofia, história, psicologia e economia sendo destacado como um dos mais importantes filósofos alemães do pós-guerra. ${ }^{9-10}$ Foi professor titular de filosofia e sociologia da Universidade de Frankfurt e entre 1971 e 1982, dirigiu o Instituto Max Planck, em Starnberg, próximo a Munique, para investigação das condições do mundo técnico e científico. ${ }^{10}$ Tornou-se um crítico contra a racionalidade instrumental da ciência e da técnica, ou seja, racionalidade científica e instrumental, julgando necessária a introdução de outra racionalidade: a comunicativa. Como consequência, ele elaborou uma teoria da linguagem e da comunicação que constitui a base de sua reviravolta linguística. ${ }^{8}$

A Teoria do Agir Comunicativo trata-se de uma obra de arquitetura complexa. 0 objetivo foi formular uma teoria orgânica da racionalidade crítica e comunicativa sob a discussão que gira em torno do agir instrumental e do agir comunicativo. ${ }^{9}$

A teoria em questão propõe que as pessoas, ao interagirem por meio da linguagem, busquem um consenso livre de interferência externa ou interna. Também está relacionada com o processo que visa o entendimento mútuo, presente em toda forma de interação. Afinal, apenas com argumentação pode-se validar proposições e legitimar normas. Portanto, a interação é a base de solução para o problema da coordenação que surge quando diferentes sujeitos que se envolvem no processo comunicativo estabelecem estratégias para um plano de ação coletivo. ${ }^{8}$

$\mathrm{Na}$ enfermagem brasileira esta busca e construção ocorreram a partir da análise das propostas político pedagógicas dos cursos de graduação e que tanto os resultados como as conclusões reafirmam a necessidade do diálogo e da busca da superação da perturbação de consenso. ${ }^{11}$

A construção comunicativa de Habermas expressa a competência da linguagem frente à validação dos atos de fala linguisticamente mediados e consiste na reconstrução do sistema de regras, segundo o qual, produzimos situações de possíveis falas. 0 ato da fala deve ser sempre proferido com o intuito de se obter um consenso, ou seja, um entendimento comum entre falante e ouvinte. Assim, não adianta os sujeitos apenas proferirem atos de fala, é necessário um acordo livre de coação e qualquer ação estratégica ou instrumental entre eles. 0 autor considera que, quando há ação estratégica e/ou instrumental, a única finalidade é a obtenção de fins desejados aliada a uma força motivadora que pode até ser entendida como manipulação. ${ }^{12}$

Ainda sob esse olhar, a razão comunicativa em Habermas considera os atos de fala e fornece força autônoma para construir uma ordem social, democrática e adequada aos seres humanos. Essa ordem acontece pela troca dos referidos atos, que devem fornecer o entendimento. Segundo o filósofo, a razão não é universal, nem pura. Ela pode ser 


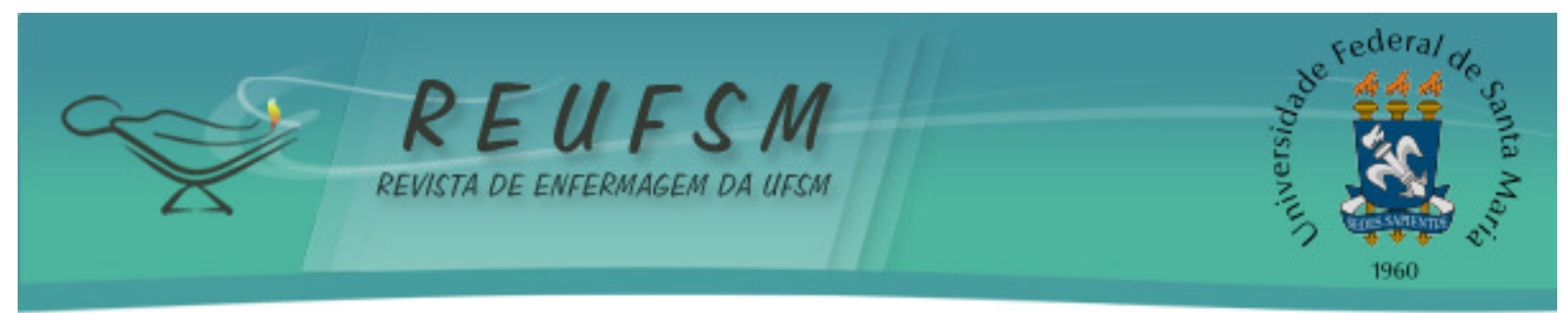

classificada de duas formas: a primeira, subjetiva e instrumental, é voltada para o domínio teórico ou prático dos objetos. A segunda - razão intersubjetiva e não instrumental envolve no mínimo dois participantes que têm como objetivo o consenso. Nesse sentido, pode-se pensar que a intersubjetividade faz parte do mundo da vida que pode ser definido como um acervo de conhecimentos transmitidos pela cultura e linguagem. Ele refere-se ao local aonde acontece o entendimento intersubjetivo por meio da linguagem. 6-7-10 $^{-1}$

\section{O agir comunicativo com o paciente crítico}

Por estar direta ou indiretamente envolvida em favor das pessoas, a enfermagem comumente é definida como um processo interpessoal. Em uma única interação há um fluxo de interferências no momento em que enfermeiro e paciente se observam e compartilham entre si pensamentos, sentimentos e atitudes. Conhecer o paciente, identificar e satisfazer suas necessidades remetem o profissional ao seu maior objetivo: assistir o indivíduo e a família, cooperando com a experiência da doença e do sofrimento. ${ }^{13}$

A dificuldade de comunicação por parte de pacientes faz com que a necessidade de cuidados para com este seja redobrada numa unidade de cuidados críticos. A ansiedade, o desconforto e a insegurança normalmente sentidos por pacientes nesse setor podem ser potencializados ao máximo para aqueles que possuem a capacidade comunicacional limitada. ${ }^{14}$

Lidar com as pessoas envolve humanização, não apenas estar atento à esfera físico-biológica e, deste modo, o sucesso ou o fracasso das interações humanas depende de como a comunicação se efetiva. Desse modo, o enfermeiro deve, em primeira instância, se comprometer com o paciente e seus familiares gerando uma relação sólida e contínua. ${ }^{13}$ Corroborando, o primeiro fator que o enfermeiro precisa reconhecer como importante para uma prática humanizada é a comunicação, pois esta, quando relacionada aos cuidados de saúde, é a prática que os pacientes mais estimam. ${ }^{1}$

Estas considerações foram confirmadas em uma pesquisa com pacientes em ventilação mecânica, em que se constatou que suas falas, após a recuperação, apontaram para satisfação em relação às formas de comunicação usadas pela equipe, as quais, segundo os sujeitos, proporcionaram alívio nos momentos angustiantes. Isto reforça a evidência de que a comunicação pode interferir no processo de recuperação do indivíduo criticamente enfermo. ${ }^{15}$

Em uma unidade crítica, frequentemente, o paciente pode se perceber em uma situação de profundo isolamento. Quanto mais intensivo é o tratamento, mais mecânico parece ser o contato dos enfermeiros com o ser humano que está à sua frente. Quanto mais isolado o paciente está, menos profissionais interagem com ele. Uma razão para isso parece ser o modelo de assistência biomédico, que prioriza o cuidado baseado na patologia e não nos sentimentos e/ou percepções que o paciente vivencia. ${ }^{2}$

Especialmente em situações de emergência, a comunicação - não raramente - é incipiente em virtude da própria condição em que se encontram os envolvidos: o profissional da saúde por correr contra o tempo; o paciente, que está em situação de perigo e a família, a qual enfrenta o medo das consequências. ${ }^{13}$

Também é importante considerar que, em ambientes de cuidados críticos, a experiência do paciente é de um tratamento invasivo, agressivo e até mesmo doloroso e, devido à gravidade de seu estado de saúde, nem sempre ele é respeitado como sujeito apto a escolher, decidir, opinar e com direito à expressão e à informação. Na maioria das vezes, por ter seu contato visual e verbal com os profissionais prejudicado, é submetido, praticamente que por completo, àqueles que the prestam cuidados, não sendo atendido de uma forma singular e sendo transformado em um receptáculo de cuidados técnicos e intensivos. ${ }^{2}$

Entretanto, o cuidar deve ser feito com o outro em um âmbito que perpasse o aspecto mecanicista. Para isto, um adequado processo comunicacional é fundamental, 


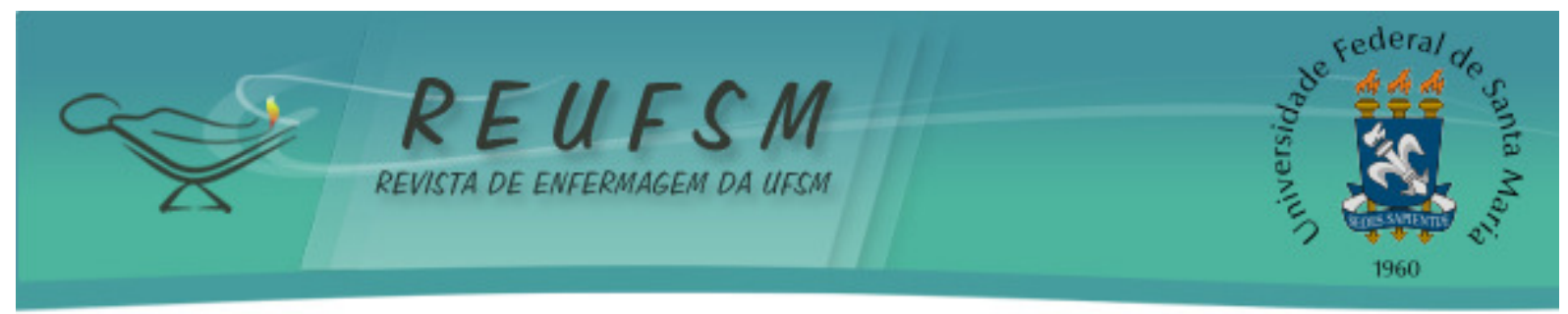

especialmente nos casos em que o cuidado é realizado a indivíduos criticamente enfermos. A comunicação adequada é aquela específica para determinada situação, pessoa, tempo e que alcança um objetivo determinado, propiciando desta maneira, um cuidado de qualidade. Contribui, pois, para a excelência da prática de enfermagem e cria oportunidades de aprendizagem para o paciente, podendo despertar sentimentos de confiança e permitindo que ele experimente a sensação de segurança e satisfação. ${ }^{14}$

A racionalidade ligada à ação comunicativa cotidiana é o que permite a prática da argumentação enquanto instância de apelação entre as ações comunicativa e instrumental. Tal fato se torna evidente quando ocorrem desacordos que não podem ser absorvidos pelas rotinas do dia a dia e nem ser decididos pelo emprego direto do poder. ${ }^{8}$

$\mathrm{Na}$ ação comunicativa, a linguagem é a verdadeira possibilidade de entendimento, pressupondo a relação entre falante e ouvinte. Dessa forma, ela passa a ser um mecanismo de coordenação da ação ajustando os planos de ação de cada indivíduo, levando-os à interação.

Com o intuito de afirmar as proposições dispostas em parágrafos anteriores, Habermas coloca que, na ação comunicativa, os agentes não se orientam pelo seu próprio êxito, mas sim pelo entendimento, o qual é determinante para a coordenação das ações. Afinal, nada pode ser aprovado como norma universal sem antes passar por uma discussão. ${ }^{6-7}$ Além disso, a ação comunicativa também consiste na prática da argumentação e reflexão, buscando a libertação da imposição de ideias que impedem a criatividade e o conhecimento crítico. Portanto, o agir comunicativo pode ser compreendido como um tipo de ação social que, por meio da intersubjetividade, busca a autonomia. ${ }^{12}$

Percebe-se com estas colocações que o agir comunicativo deve estar inteiramente inserido nas ações de enfermagem, cabendo em especial ao enfermeiro, desvendar o significado das mensagens que os pacientes enviam para que possa ser instituído um melhor plano de cuidados. É essencial saber interpretar que a maneira como o paciente percebe os acontecimentos à sua volta influencia a sua conduta mais do que a realidade da situação em si. ${ }^{2}$

Portanto, o enfermeiro deve possuir conhecimentos fundamentais sobre as bases teóricas da comunicação e desenvolver habilidades de relacionamento interpessoal, agindo positivamente na assistência prestada ao doente. A priorização da comunicação requer do profissional uma mudança de foco e atitude para perceber como os diferentes contextos de cuidado são vivenciados pelos pacientes críticos. Perceber constitui não apenas olhar, mas atentar e identificar as diferentes dimensões do outro, valorizando suas experiências, comportamentos, emoções e espiritualidade. ${ }^{1}$

É necessário que a equipe de enfermagem atente-se sobre o seu papel como elo entre o paciente e seus familiares, tal qual com outros profissionais de saúde. 0 relacionamento entre equipe de saúde, paciente e família deve ter por objetivo auxiliar o doente de forma alicerçada a atingir um sentido mais amplo, que é o de um relacionamento terapêutico, entendido como processo interativo, envolvendo afinidade, compreensão e aceitação. ${ }^{13}$

Em um ato de fala, os sujeitos podem se referir ao mundo objetivo, social e subjetivo, representando a linguagem em suas funções representativa, interativa e expressiva, respectivamente. Cada uma dessas esferas corresponde a um fragmento do mundo da vida, que é um saber intuitivo que se predomina por viver numa mesma cultura e compartilhar as mesmas experiências e corresponde a tradições culturais, solidariedades sociais em conjunto com estruturas da personalidade. ${ }^{8}$

Em síntese, o agir comunicativo possibilita uma interação plena entre os seres humanos, substituindo as relações assimétricas que a impedem. 0 ator é ao mesmo tempo o iniciador que domina as situações por meio de ações e produto das tradições em que se encontra, dos grupos aos quais pertence e dos processos de socialização em que são criados. Este tipo de agir apenas se efetuará quando os atores sociais harmonizarem internamente seus planos de ação e perseguirem suas respectivas metas. ${ }^{4}$ 


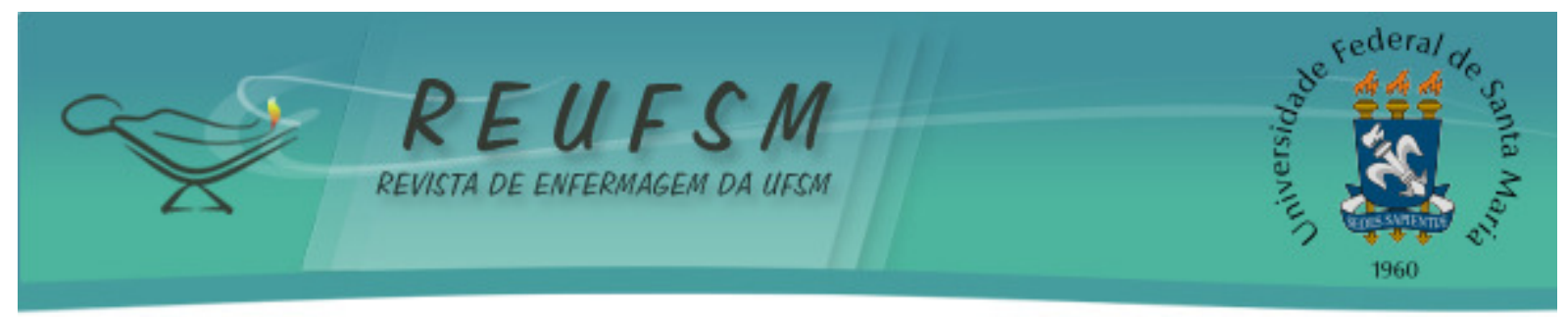

O enfermeiro precisa verificar se suas ações são apenas pautadas no agir estratégico. Se o forem, não raramente haverá a possibilidade de ele se deparar com a falta de entendimento. Portanto, para subsidiar seu agir, este profissional deve buscar elementos das ciências sociais e sensibilização (sensibilizar-se) sobre a importância da comunicação no processo de cuidar, de maneira que possa transformar a relação enfermeiro-paciente em uma relação com uma comunicação efetiva. Quando a enfermagem atuar embasada no agir comunicativo poderá propiciar entendimento e grandes transformações sociais. ${ }^{4}$

\section{CONSIDERAÇÕES FINAIS}

Por meio da análise da literatura conclui-se que a Teoria da Ação Comunicativa de Jurgen Habermas pode contribuir na melhoria da assistência de enfermagem ao paciente em estado crítico, visto que, ao submeter suas atitudes a um agir comunicativo, o enfermeiro estará em busca de uma maior interação com o paciente, família, sua equipe e demais profissionais da saúde.

Atualmente, os recursos humanos da área da saúde não estão engajados em desenvolver suas habilidades linguísticas, o que torna o cuidado muitas vezes um ato mecânico, desprovido de humanização. Em ambientes críticos, também há o agravo de que parte dos pacientes têm sua comunicação prejudicada de alguma forma, tornando difícil o acesso da equipe de enfermagem a dados relevantes sobre os mesmos.

Essa situação se configura em um obstáculo para que seja adquirido um agir comunicativo nesta ambiência, uma vez que a interação entre equipe e paciente pode estar comprometida. Entretanto, embora haja a dificuldade, ela não pode se traduzir como impossibilidade de prestar um cuidado humanizado e de qualidade, e a comunicação efetiva do enfermeiro poderá representar uma mola propulsora para transpor este obstáculo.

$\mathrm{Na}$ perspectiva de trabalhar incansavelmente para a transformação de uma realidade, os enfermeiros devem observar, sentir, desvendar e acompanhar a comunicação, vislumbrando-a como agente de mudanças. É necessário estar sensibilizado acerca da sua importância no processo de cuidar, especialmente em ambientes críticos, onde os pacientes muitas vezes vivenciam o auge de sua dependência em relação ao cuidador, bem como alcança níveis máximos de carência de seus familiares. Nesse contexto considera-se que linguagem, cultura, trabalho, personalidade, diálogo e comunicação formam uma sólida estrutura para a conquista da autonomia humana.

Levando em conta que Habermas sugere que a interação é indispensável para a organização social, o entendimento mútuo deve ser visado buscando sempre o consenso de forma livre de qualquer coação.

0 agir do enfermeiro com seu público-alvo visa à promoção da saúde, ao seu bemestar e, acima de tudo, ao reestabelecimento de sua saúde nos casos de internamento em unidades críticas. Para tanto, tal profissional dispõe de um rico contexto de relacionamento interpessoal. Ter uma atitude comunicativa certamente deve ser uma preocupação de todos os profissionais que em seus cotidianos lidam com a prestação de cuidados, pois toda comunicação com responsabilidade ética já é uma forma de cuidado.

Distante de finalizar as reflexões e discussões sobre a temática em questão espera-se que esse estudo seja o início de novas reflexões e que possa subsidiar enfermeiros que atuam em áreas críticas e instigá-los pela busca incessante de um cuidado humanizado e por uma mudança de atitude capaz de transformar ações estratégicas e instrumentais em um agir comunicativo. 


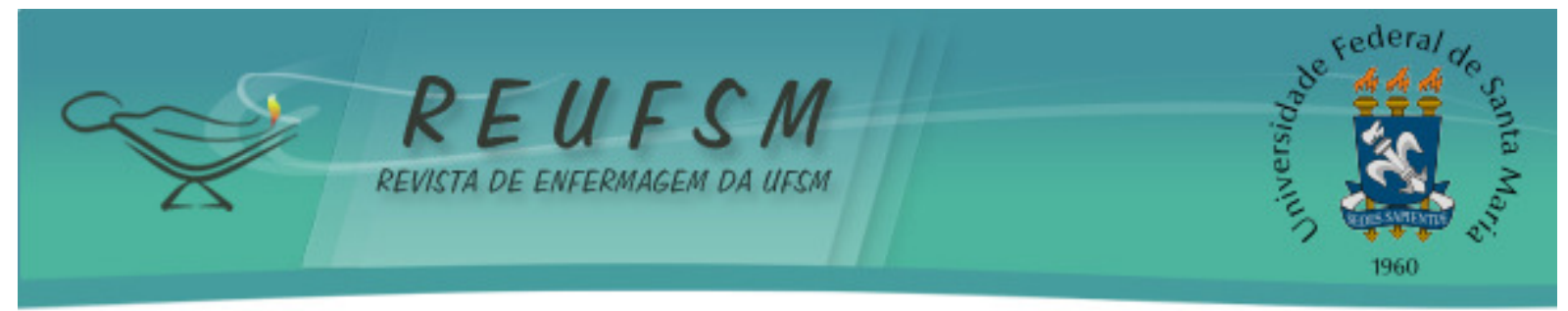

\section{REFERÊNCIAS}

1. Mourão CML, Albuquerque AMS, Silva APS, Oliveira MS, Fernandes AFC. Comunicação em enfermagem: uma revisão bibliográfica. Rev RENE [Internet]. 2009 [acesso em 2012 jul 1];10(3):139-45. Disponível em: www.revistarene.ufc.br/vol10n3_pdf/a17v10n3.pdf.

2. Barlem ELD, Rosenhein DPN, Lunardi VL, Lunardi Filho WD. Comunicação como instrumento de humanização do cuidado de enfermagem: experiências em unidade de terapia intensiva. Rev Eletrônica Enferm [Internet]. 2008 [acesso em 2012 jan 31];10(4):1041-9. Disponível em: http://www.fen.ufg.br/revista/v10/n4/v10n4a16.htm.

3. Morais GSN, Costa SFG, Fontes WD, Carneiro AD. Comunicação como instrumento básico no cuidar humanizado em enfermagem ao paciente hospitalizado. Acta Paul Enferm. 2009;22(3):323-7.

4. Larocca LM, Mazza VA. Habermas e Paulo Freire: referenciais teóricos para o estudo da comunicação em enfermagem. Rev Gaúch Enferm. 2003;24(2):169-76.

5. Oliveira OS, Nóbrega MML, Silva ANTC, Ferreira-Filha MO. Comunicação terapêutica em enfermagem revelada nos depoimentos de pacientes internados em Centro de Terapia Intensiva. Rev Eletrônica Enferm [Internet]. 2005 [acesso em 2013 abr 18];7 (1):54-63. Disponível em: http://www.revistas.ufg.br/index.php/fen/article/view/861.

6. Habermas J. Consciência moral e agir comunicativo. Rio de Janeiro (RJ): Tempo Universitário; 1989.

7. Habermas J. Teoria do agir comunicativo. São Paulo (SP): Martins Fontes; 2012.

8. Machado MMT, Leitão GCM, Holanda FUX. O conceito de ação comunicativa para a consulta de enfermagem. Rev Latinoam Enferm. 2005;13(5):723-8.

9. Oliveira PC. A ética da ação comunicativa em Jurgen Habermas. Rev estudos filosóficos [Internet]. 2008 [acesso em 2012 fev 15];(1):14-22. Disponível em: http://www.ufsj.edu.br/portal2-repositorio/File/revistaestudosfilosoficos/art2-rev1.pdf.

10. Nascimento SR. O agir comunicativo permeando as tecnologias educacionais na construção do conhecimento em enfermagem [tese]. Florianópolis (SC): Universidade Federal de Santa Catarina; 2005. 170 p.

11. Alves, ED. O agir comunicativo e as propostas curriculares da enfermagem brasileira. Pelotas (RS): Editora UFPEL; 2000.

12. Lodéa AL. Entendimento e linguagem: uma compreensão da teoria da ação comunicativa de Jurgen Habermas. Guairacá [Internet]. 2010 [acesso em 2012 mar 23];(26):55-79. Disponível

http://revistas.unicentro.br/index.php/guaiaraca/article/viewFile/1848/1616.

13. Tigulini RS, Melo MRAC. A comunicação entre enfermeiros, família e paciente crítico. In: Anais do $8^{\circ}$ Simpósio Brasileiro de Comunicação em Enfermagem; 2002 maio 2-3; São Paulo, SP, Brasil [Internet]. 2002 [acesso em 2012 set 25]. Disponível em: http: / / www.proceedings.scielo.br/scielo.php?script=sci_arttext\&pid=MSC000000005200200 0200047\&lng=en\&nrm=van.

14. Inaba LC, Silva MJP, Telles SCR. Paciente crítico e comunicação: visão de familiares sobre sua adequação pela equipe de enfermagem. Rev Esc Enferm USP. 2005;39(4):423-9. 


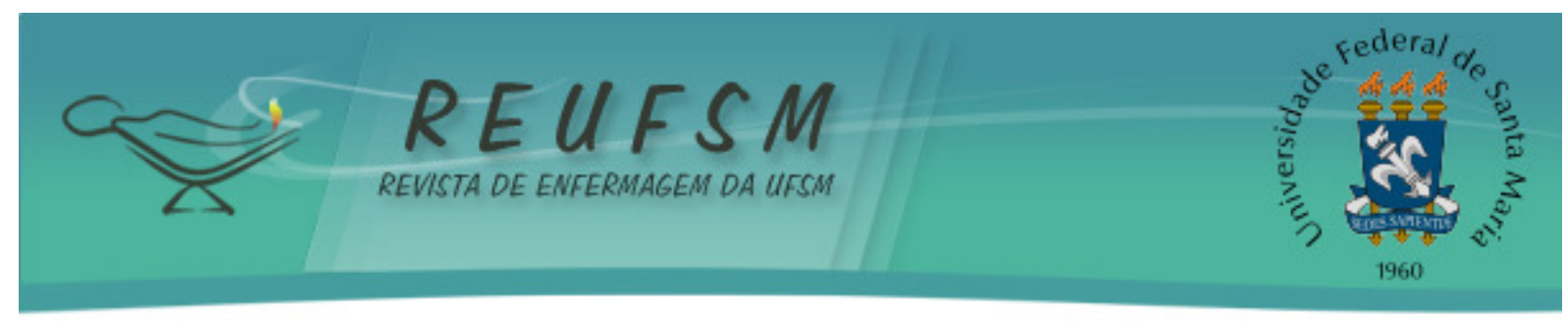

15. Vargas JS, Rezende MS. Comunicação: equipe de enfermagem e paciente em ventilação mecânica. Rev Enferm UFSM [Internet]. 2011 [acesso em 2012 nov 11];1(3):412-9. Disponível em: http://cascavel.ufsm.br/revistas/ojs2.2.2/index.php/reufsm/article/view/3380/2391.

Data de recebimento: 10/12/2012

Data de aceite: 07/05/2013

Contato com autor responsável: Juliana Helena Montezeli

Endereço postal: Rua Jorge Velho, 270, AP.402, Jd. Ipiranga, Londrina-PR, CEP: 86010-600

E-mail: jhmontezeli@hotmail.com 